\title{
Interatrial Block and Risk of Ischemic Stroke - Reply -
}

\author{
Jin-Tao Wu ${ }^{1}$, De-Yong Long ${ }^{2}$ and Shan-Ling Wang ${ }^{1}$ \\ ${ }^{1}$ Department of Cardiology, Henan Provincial People's Hospital (Zhengzhou University People's Hospital), Zhengzhou, China \\ ${ }^{2}$ Department of Cardiology, Center for Atrial Fibrillation, Beijing Anzhen Hospital, Capital Medical University, Beijing, China
}

\section{Author's Reply}

We have read the letter from Prof. MartínezSellés $e t a l^{1)}$, and we are grateful for their comments regarding our study ${ }^{2}$ and for bringing forward two relevant issues for discussion.

The first issue pertains to the necessity of differentiating advanced from partial interatrial block (IAB) in our study population. Based on its degree, IAB is classified into partial ( $\mathrm{P}$-wave duration $\geq 120 \mathrm{~ms}$ ) or advanced IAB (P-wave duration $\geq 120 \mathrm{~ms}$ with biphasic $[ \pm]$ morphology in inferior leads $)^{3)}$. In our study, $\mathrm{IAB}$ was analyzed in a global manner, and no distinction was made regarding the degree of this condition. We agree that it would have been better to differentiate advanced from partial IAB in our study population, as this may have provided data regarding the relative prognostic performance of the $\mathrm{CHADS}_{2}$ and $\mathrm{CHA}_{2} \mathrm{DS}_{2}$-VASc scores for predicting the risk of ischemic stroke or transient ischemic attacks (TIA) in patients with different degrees of IAB without known atrial fibrillation (AF). However, although the prevalence of partial IAB has been described as an underappreciated clinical "pandemic"4), the prevalence of advanced IAB is very low in the general population $(0.5 \%)^{5}$. Further, because the association of advanced $\mathrm{IAB}$ with $\mathrm{AF}$ is higher than that with partial $\mathrm{IAB}^{6}$, more patients with advanced IAB may have known AF at baseline. Thus, more patients with advanced IAB were excluded from our study population because our study aimed to address issues in populations without known AF at baseline. Therefore, future studies with larger sample sizes are needed to assess the relative predictive value of the $\mathrm{CHADS}_{2}$ and $\mathrm{CHA}_{2} \mathrm{DS}_{2}-$ VASc scores for ischemic stroke or TIA in advanced and partial IAB patients without known AF at base-

Address for correspondence: Shan-Ling Wang, Department of Cardiology, Henan Provincial People's Hospital (Zhengzhou

University People's Hospital), Zhengzhou, China

E-mail: ycksyy@126.com

Received: July 29, 2016

Accepted for publication: August 1, 2016 line.

The second issue pointed out by Prof. MartínezSellés et al. pertains to the measurement of P-wave duration. To the best of our knowledge, there is no consensus on how to measure $\mathrm{P}$-wave duration. In our study, it was measured in each of the 12 electrocardiogram (ECG) leads to identify the maximum P-wave duration in any lead. This method has been described and validated in previous studies ${ }^{7-9)}$. Additionally, the definition of IAB is based only on the maximum P-wave duration in any of the 12 ECG leads, which was also adopted in a previous study conducted by Caldwell et $a l^{9)}$. Prof. Martínez-Sellés et al. innovatively used a program called GeoGebra to interpret ECG on the computer. By doing so, the error of measurement with this application was very low. We are very interested in their innovative method and plan to attempt ECG interpretation with this application in our future research.

\section{Conflicts of Interest}

The authors have no conflict of interest.

\section{References}

1) Martínez-Sellés M, Alberto Escobar Robledo L, Baranchuk A: Interatrial block and the risk of ischemic stroke. J Atheroscler Thromb, 2017; 24: 185-186

2) Wu JT, Wang SL, Chu YJ, Long DY, Dong JZ, Fan XW, Yang HT, Duan HY, Yan LJ, Qian P: CHADS2 and CHA2DS2-VASc scores predict the risk of ischemic stroke outcome in patients with interatrial block without atrial fibrillation. J Atheroscler Thromb, 2017; 24: 176184

3) Bayes de Luna A, Platonov P, Cosio FG, Cygankiewicz I, Pastore C, Baranowski R, Bayes-Genis A, Guindo J, Vinolas X, Garcia-Niebla J, Barbosa R, Stern S, Spodick D: Interatrial blocks. A separate entity from left atrial enlargement: a consensus report. J Electrocardiol, 2012; 45: $445-451$

4) Chhabra L, Devadoss R, Chaubey VK, Spodick DH: Interatrial block in the modern era. Curr Cardiol Rev, 2014; 10: 181-189 
5) O'Neal WT, Zhang ZM, Loehr LR, Chen LY, Alonso A, Soliman EZ: Electrocardiographic advanced interatrial block and atrial fibrillation risk in the general population. Am J Cardiol, 2016; 117: 1755-1759

6) Martínez-Sellés M, Massó-van Roessel A, Álvarez-García J, García de la Villa B, Cruz-Jentoft AJ, Vidán MT, López Díaz J, Felix Redondo FJ, Durán Guerrero JM, BayesGenis A, Bayes de Luna A; Investigators of the Cardiac and Clinical Characterization of Centenarians (4C) registry: Interatrial block and atrial arrhythmias in centenarians: Prevalence, associations, and clinical implications. Heart Rhythm, 2016; 13: 645-651

7) Dilaveris P, Batchvarov V, Gialafos J, Malik M: Comparison of different methods for manual $\mathrm{P}$ wave duration measurement in 12-lead electrocardiograms. Pacing Clin Electrophysiol, 1999; 22: 1532-1538

8) Andrikopoulos GK, Dilaveris PE, Richter DJ, Gialafos EJ, Synetos AG, Gialafos JE: Increased variance of $P$ wave duration on the electrocardiogram distinguishes patients with idiopathic paroxysmal atrial fibrillation. Pacing Clin Electrophysiol, 2000; 23: 1127-1132

9) Caldwell J, Koppikar S, Barake W, Redfearn D, Michael K, Simpson C, Hopman W, Baranchuk A: Prolonged $\mathrm{P}$-wave duration is associated with atrial fibrillation recurrence after successful pulmonary vein isolation for paroxysmal atrial fibrillation. J Interv Card Electrophysiol, 2014; 39: 131-138 